\title{
NATIONAL HEALTH INSURANCE: A REVIEW OF POLICIES AND PROPOSALS
}

\author{
I. S. FALK*
}

I

\section{The Insurance Dilemma}

Current discussions of national health insurance are based, first, on a commitment that medical care should be available to everybody and, second, on a belief that the costs of medical care should be met through group payment. The commitment to availability reflects a basic social policy stemming from widespread belief that no one in modern society should suffer because medical care is not available when and where it is needed. The consensus favoring group payment, or cost sharing, derives from the fact that the costs of medical care are not reliably manageable on an individual or family basis because of the uncertain and variable nature and the potential size of the costs for any particular family in relation to its private resources. Because availability of medical care has become in larger and larger measure a matter of cost, the two threads-the concern for availability and the need for cost sharinghave become permanently intertwined, and the issue of national health insurance is the culmination of these originally severable concerns.

The social policy favoring universal availability of health care has emerged in the past decade and is increasingly referred to as the "right to medical care." The compelling need for group payment of costs has become increasingly clear in the four decades since the characteristics of these costs were comprehensively demonstrated by the Committee on the Costs of Medical Care, ${ }^{1}$ and year by year these costs have continued to increase faster than other costs for the essentials of living and faster than private resources to pay for personal health services.

Group payment of medical care costs requires decisions about the categories of costs to be paid on a group basis, the size of the population group whose costs are to be pooled, the mechanism of payment, and the source of the funds. The world has had centuries of experience with these questions and problems. In the United States, after limited experience for a century or more, we have had four decades of large-scale experience with private and governmental health insurance programs. Our experiences have been diverse, featuring both narrow and broad coverage of costs; both small and large population groups; reliance on both individual private resources

\footnotetext{
- Professor Emeritus of Public Health (Medical Care) and Lecturer, Yale University School of Medicine; and Chairman, Technical Subcommittee, Committee for National Health Insurance.

${ }^{2}$ See I. Falk, M. Klem, \& N. Sinal, The Incidence of Illness and the Receipt and Costs of Medical Care Among Representative Families (I933); I. Fazk, C. Rorem, \& M. Ring, The Costs of Medicar Care (I933).
} 
and the capacity of the employment contract to carry part or all of the medical costs; varied uses of the fiscal resources of local, state, and national governments; and great experimentation in combining these various elements. The result has been a massive success in extending some participation in group payment schemes to most of the population-whether through private insurance or governmental provisions-and, at the same time, a massive failure to provide adequate or effective group payment.

Nearly all of the population sixty-five and over has some group payment of medical care costs through the national Medicare program. Many of the poor and near-poor have some corresponding group payment through the federal-state public assistance and related programs. Large proportions of those who are in the labor force and substantially employed have some group payment through employment-related private group insurance. Over forty million have group payment through privately purchased individual insurance contracts. ${ }^{2}$ And nearly all who are not in these categories have some other form of complete or partial public or private protection against medical care costs, as members of the armed forces, veterans, insurancecovered retirees from public or private employments, wards of government, beneficiaries of private charities or of categorical governmental service programs, and so forth. In short, nearly everybody has some group payment coverage, and the insurance industry, nonprofit and commercial, can justifiably lay claim to having reached $150-185$ million persons with some private health insurance protection.

Another picture emerges, however, when the achievement is measured in terms of the extent of the protection afforded. Of the $\$ 59.7$ billion of total expenditures for personal health services (including the costs of effecting prepayment) in fiscal year 1970, governmental outlays (federal, state, and local) provided thirty-four per cent, and all private payment sixty-six per cent. Of the private expenditures for these services $-\$ 39.2$ billion in that year-private insurance cost $\$ 15.5$ billion; it paid out $\$ 13.8$ billion for benefits or thirty-five per cent of all private expenditures, and left $\$ 25.4$ billion (including the costs of insurance) or sixty-five per cent to be paid out-of-pocket by the private consumers. ${ }^{3}$ The thirty-five per cent coverage ratio reflects a growth from about ten per cent in fiscal year 1950, but it has been increasing by a scant percentage point per year in recent years.

The $\$ \mathrm{r} 3.8$ billion paid out last year through private insurance gave vast relief to millions of persons with medical care expenses that came within the protections of the contracts; the $\$ 25.4$ billion expended privately out-of-pocket comprised millions of individual expenditures that were small and readily manageable but also millions of expenditures that were burdensome or even catastrophic. Since generally no family could anticipate or control in which category its experience would fall, millions of families found that year-as others had found before them-that the purchase of limited private insurance can be inadequate. And the dissatisfaction

\footnotetext{
${ }^{2}$ Mueller, Private Health Insurance in r969: A Review, 34 Sociar. Secunity Bull., Feb. 197x, at $x$.

sice \& Cooper, National Health Expendittres, 1929-1970, 34 SociaI Securiry BuLL., Jan. t97x, at 3 .
} 
had been especially prevalent among those whose personal expenditures were in addition to premiums for insurance which the purchasers had thought would be broad or all-inclusive. The satisfactions and dissatisfactions have not offset each other, because no family with insurance and occasion to pay medical care costs could know in which category it would fall.

Long ago, when medical care costs amounted to less than four per cent of gross national product, they were manageable when regarded in the average. But even the earliest studies showed that one of the main problems they presented resulted from the variation of costs for individual families-whether in the course of a year or over a lifetime-and thus demonstrated the need for group payment to substitute the manageable average for the unmanageable individual and variable cost. Even those early studies showed that in each of the main categories of medical care (medical, surgical, dental, hospital, medicines, and so forth) costs could vary significantly from the mean and that adequate and effective protection required that the group payment extend to all categories in which the variability was considerable and frequent. It is obvious, then, that if insurance extends mainly to particular categories of costssay, surgical and hospital costs-it will be effective for those who incur substantial costs only in those categories and will fail to give protection to those persons so unfortunate as to experience illnesses involving large costs in noncovered or in excluded categories. And if the insurance extends to only part of each categorical cost-requiring "deductibles" and "copayments" or being subject to exclusions or limiting durations-it may not be adequately effective in large proportions of costly illnesses or for large proportions of families with modest fiscal resources.

These lessons have been driven home more and more emphatically as personal health service expenditures have increased about seventeen-fold while population was merely doubling between 1930 and 1970 , having increased from $\$ 3.3$ billion for about roo million persons to $\$ 59.7$ billion for about 200 million persons. Each major category of expenditure has increased greatly, and each has come to have greater potential for variability and thus for catastrophic impact on individual family budgets.

When the earliest of modern studies portrayed the characteristics of medical care costs and demonstrated why the population needed group payment, there were serious differences of opinion whether the needed rational system of payment could be effected through private insurance or whether it required instead the intervention of government and the compulsion of public law. ${ }^{4}$ The pioneering study group advised that if undertaken on a private and voluntary basis it should be done by nonprofit organizations-that this was not a field for profit-motivated commercial undertaking because participation by commercial insurance companies would tend to increase the costs and not to improve the quality of service. ${ }^{5}$ Nevertheless, for

\footnotetext{
'See The Committee on the Costs of Medtcal Care, Medical Care for the American People (1932).

${ }^{5}$ Id. at 50.
} 
about thirty-five years (1930-I965) the main development of group payment (except for the poor and near-poor assisted on a means-test basis and for others in special categories receiving government support) was in the private sector and increasingly through commercial insurance companies rather than through nonprofit organizations like Blue Cross, Blue Shield, or independent prepayment plans.

As private group payment expanded and yet kept failing to provide adequate protection, its failure led to increasingly strong advocacy of government intervention, especially with respect to those in the population for whom private coverage was least adequate. This movement came to a first end-point in 1965 when Medicare was enacted to provide a national health insurance of sorts for those sixty-five and overa mixture of paid-up compulsory hospital insurance and voluntary current supplementary medical-care insurance. This was in effect an "exempting-out" for older persons from reliance on private insurance to effect group payment. Since 1965 the broader question has persisted: Can private insurance, relieved of responsibility for meeting the needs of older persons with their higher-than-average risk rates and costs, achieve acceptable levels of insurance protection, or must the intervention of government extend from the aged to other categories-or to all others-in the population? Between 1965 and 1970 private insurance protection, even though largely relieved of covering the aged, rose by one percentage point a year-from thirty per cent to thirty-five per cent of private costs for personal health services. ${ }^{6}$ Apparently, the private mechanism cannot achieve much more than about one-third protection whereas adequacy requires about eighty per cent or possibly somewhat more.

Dissatisfaction with private insurance does not derive only from its quantitative inadequacy in providing insurance protection. Other serious deficiencies apply in different measure to the several categories of insurance carriers. Fragmentation of insurance, such as Blue Cross coverage of hospitalization costs and Blue Shield coverage of surgical and inpatient attendance costs, invites and encourages in-hospital services. Selective and limited coverages by insurance company contracts similarly invite utilization of those services whose costs are indemnified under those contracts. As a result we have had decades in which the prevalent mechanisms for private group payment of private costs have had large influence not only in supporting the existing patterns for the delivery of medical care but also in steadily distorting the patterns toward fragmentation of services and excessive utilization of particular categories of service. Having guarantees of payment to sustain them, the insurance-supported services understandably led the way in escalation of prices as well as in volumes of utilization. The relative simplicity of paying hospital costs, whether on a cost-reimbursement or on an indemnity basis, and of paying surgical costs on a surgical fee schedule basis, cultivated the patterns of reliance on hospital

\footnotetext{
- Rice \& Cooper, supra note 3; Skolnik \& Dales, Social Welfare Expenditures, 33 SoctuL SEcunity BuLl., Dec. 1970, at 3 .
} 
services and surgery and the patterns of resource development and utilization which plague the current scene.

The influence of these payment mechanisms and patterns did not apply only to the private-sector programs. In Medicare for the aged and Medicaid for the poor and near-poor, the combined influence of providers and insurance carriers has led to implantation of these patterns-so profitable to them in the private services-in the tax-financed programs. The result has been fiscal near-disaster in the public programs, expressed in anguished outcries from legislators entrapped into supporting levels of tax appropriations far beyond their expectations and the nation's.?

Here, then, is the course which has been run by the prevailing patterns of private group payment. In its modern form it was first undertaken to help in paying limited portions of medical care costs on a group basis. It brought great public satisfactions and even greater expectations. Then it began to create incentives for unduly high utilization of expensive human and institutional resources which fits the insurance carriers' patterns of payment. This required higher and higher group payment premiums to support higher fees and mounting operating costs. Then, as the rising costs met inevitable resistances, the carriers were compelled to adhere to the limited scope of payment coverages and to the patterns of service organization, costs, and charges which suited their accustomed methods of payment.

During the past two decades the nation has become first concerned and then outraged by the continuing escalation of medical care costs at a pace much faster than the rise in prices generally and faster than the rapid growth of the national economy. Gradually the conviction grew that the medical care financing systems themselves were contributing to the creation of the rising costs and were themselves entrapped in their own mechanisms-as well as being supported by the cost and charge practices of the principal providers of services. A revolt was brewing, though the form it would take and the changes it would invite were not clear.

Then, almost suddenly, especially after 1965 , a consensus began to emerge to the effect that the difficulties over costs and payments did not stand alone and could not be dealt with alone. Despite higher and higher costs, charges, and payments, public as well as private, medical care was becoming increasingly difficult to obtain, and large areas and population groups were seriously underserved. Comprehensiveness of services was not being achieved despite the enlarging of expenditures. Quality of care was getting no better for many people, despite widely publicized expansion of medical knowledge and achievement of promising new medical skills. The institutions responsible for professional and technical education and training of the health manpower needed for a growing population and for the expanding demand for health services were in progressively deepening fiscal straits. The whole medical care system-or "nonsystem" as many began to call it-was in trouble and needed an overhauling.

\footnotetext{
'See Staff of Senate Comm. on Finance, gist Cong., ist Sess., Medicare and Medicatd: ProbIems, Issues, ANd Alternattves (Comm. Print r970).
} 
As the trouble began to become evident and acute in the past two decades, there was at first-between $195^{\circ}$ and 1965 -massive resistance to change from those who were content with the status quo. Their resistance was partially overcome in 1965-1967 when the Congress enacted Medicare and various other programs. But since dominating compromises with the status quo had been built into those newer public programs, each of them was soon in the difficulties it had been intended to avoid. The difficulties and disaffections continue, and the public outcries grow louder. A spreading conviction that medical care in the United States is in trouble was capped-off by President Nixon's statement in July Ig69 that America's medical system faces a "massive crisis" and by his later conclusion: "Since that statement was made, that crisis has deepened."

The needs which had started with fiscal problems are now multi-dimensional. The "insurance dilemma" has now been overtaken by focus on modernization of the "delivery system."

\section{II}

\section{The Medical Care Crists: Muuttple Causes and Negds}

The medical care "industry" is now one of the largest in the country, measured by the annual national expenditure of about $\$ 75$ billion (about $\$ 365$ per capita) for health services and goods, construction of health service facilities, and performance of medical research. ${ }^{9}$ It is also in many respects the most complex, especially because of its labor-intensiveness and the almost endless intricacy of its technology. It is therefore not surprising that when such an industry is "in crisis" on a national scale, the problems and the needs for dealing with them are diverse and difficult.

Broad consideration of the major causes of crisis in medical care begins with the fiscal difficulties, the relatively high costs and comparatively steep annual escalations, but the list of causes goes on to include areas which present even more complex and more perplexing questions than does the issue of finances. A hundred problems could be enumerated, but upon inspection they can be subsumed in the following four categories, usefully in this sequence:

I. national shortages in various categories, both old and new, of health manpower and facilities;

2. steeply rising costs and their financing;

3. inadequacies in the system for assuring availability and delivery of needed services; and

4. lack of sufficient and effective controls for the assurance of quality of care.

\footnotetext{
${ }^{8}$ Message from the Prestdent of the United States Relative to Bullding a National Healmt Stratect, H.R. Doc. No. 92-49 at 19, 92d Cong., Ist Sess. (Feb. 18, r97I).

- But excluding over $\$ \mathrm{I}$ billion for the education and training of medical personnel (except in hos. pitals) and most of the expenditure by state and local governments and by the private sector for air pollution and water pollution control, sanitation, water supplies, and sewage treatment.
} 
These causes of crisis are not discrete. On the contrary, they are interlocked one with another, and, indeed, the difficulties of dealing with the interrelations among them might fairly be regarded as a fifth major cause. Therefore, if we are to surmount the crisis, we must deal with all four categories of cause and with their interrelations.

There are some who counsel and advocate that we should deal with each category separately and on its own convenient time schedule-essentially a continuation of the policies the nation has been following for decades. This is a counsel of caution but not of wisdom. Consider the consequences of further categorical pursuits. What will it avail us if we merely try to produce more manpower or facilities without assuring the availability of funds and a better system for their utilization? Is it likely that we can contain the escalation of costs without a better system for the containment of unit costs of service and for the assurance of economy in volumes of utilization? Is it reasonable to expect that we can have or can afford either needed health manpower and facilities or assured and adequate financing without a better system of delivery? Can either the professions or the public go much longer without better protections of quality and adequacy of care? Can the provision of more purchasing power for medical care be contemplated alone-without improvement in the system for delivery of care-since an expansion of effective demand would invite further strain on the resources for service and would surely increase the upward push of prices?

Consequently, whether taking shortage of resources, or costs and their financing, or system improvements, or quality assurances as a starting point, the nation must also look to all the other causes of difficulty. If we do less than this, or if we delay in commitment to an adequate program, we will surely find ourselves in a worsening crisis from which our escape will be increasingly difficult and heroic. Any doubt on this score should be dissipated by the fiscal trends alone. Expenditures are escalating at the rate of ten to fifteen per cent a year, and the prospects are that, if the current trends are permitted to continue, medical care costs, which have already reached about $\$ 75$ billion a year (more than seven per cent of gross national product), are pointed toward reaching \$1ro-\$r2o billion in 1975 and $\$ 156-\$ 189$ billion in $x 980$-climbing to eight to ten per cent of an increasing GNP..$^{10}$

It must be clear that merely instituting a bigger or even a better health insurance program-whether governmental or private or mixed-will not suffice. Better fiscal provisions must be accompanied by provision for more adequate health manpower and facilities, for their more effective utilization, for the achievement of economies without sacrifice of quality, for moderation if not containment of cost escalations, and for better access to medical care services, especially for those of modest or small means who now have difficulty in obtaining needed care.

\footnotetext{
${ }^{10}$ D. Rice \& M. MCGee, Projections of National Health Expenditures, I975 and ig80 (Social Security Administration Research and Statistics Note No. I8, 1970).
} 
Other countries have been confronted with needs not greatly different from ours, and some have met their problems by adopting and implementing the design of a national health service in which government owns and operates the hospitals and other facilities, employs the personal providers of medical care, and finances the program from the national fiscal resources. This is a recourse for which there is neither need nor occasion in the United States and no substantial supporting sentiment or demand. On the contrary, the current and prospective problems and needs focus on three separable but related questions:

(x) What should be the role of government (at each level) in providing the framework for a better, and hopefully an adequate, system of medical care?

(2) What should be the role of and the mechanism used by government in the financing of the better program?

(3) What improvements should the financing system undertake to stimulate in the private sector for the provision and availability of services?

This is, in a sense, a prescription for a declaration of goals and for finding a way out of the crisis. Expressed in this fashion, the prescription invites a continuing partnership of the public and the private sectors, the public mainly for program design and financing and the private mainly for provision of services. The financing may be nationally uniform or diverse; the provision of services is already diverse and can be encouraged to continue to be experimental and evolutionary as medical practices adapt to the state of the art.

It is noteworthy that among the many proposals already before us on the national scene for dealing with medical care needs, none is for a national health service. Not one advocates expanded intervention of government in the ownership, operation, or provision of personal health services, but all proposals contemplate increased intervention of government in the design of a prospective program and in its financing.

\section{III}

\section{Policies and Specifications for a National Program}

There is now an emerging consensus in the United States on a social policy that would assure the availability of medical care to everybody. This reflects an almost universal agreement that medical care ranks with food, shelter, and clothing as an essential of living, and that it is embraced by the obligation of society to ensure that no one suffers a basic want. The goal of this social policy is widely accepted, even if there are differences about ways and means for its attainment. ${ }^{11}$

Medical care in a modern sense is not made available to all persons merely as a result of the emergence of a social commitment or even by a clear statutory declaration about the "right to medical care."12 To be truly available it must meet criteria which

\footnotetext{
${ }^{11}$ Falk, Medical Care and Social Policy, 55 AM. J. Pur. Hearth 522 (1965).

${ }^{12}$ For a bibliography of recent publications on the "right to health care" consult J. CArMOdY, Etrrent
} 
are complex and exacting. It must be comprehensive in scope, of good quality according to the potentials and standards of the times, obtainable under socially and psychologically acceptable conditions, and actually available according to medical need without the barrier of individual inability to pay, insurance contribution history, or means test of eligibility for private or public charity.

I would suggest that attainment of this social goal must, as a minimum, reflect three precepts:

(a) Technological progress and complexity compel the availability, provision, and delivery of comprehensive personal health services through locally and regionally organized group practices. ${ }^{13}$

(b) The nature of medical care costs requires that they be financed through group payment-and not by the sick alone but largely by the well, so that the costs will not be a barrier when the care is needed or a burden after it has been received.

(c) Financing must rest upon the resources of the whole national economy, avoiding economic and fiscal diversities among states, localities, employments, and families.

From these positions of policy, goals, and precepts, a series of specifications follows which, I believe, should then guide the design of a good and adequate national proposal:

(I) The whole population should be eligible for all the benefits of the program, according to the need for health care and without financial tests or barriers.

(2) The program should undertake to assure the availability of all useful and promising medical care services within the spectrum of its benefits.

(3) The desired organizational pattern and delivery system should, as a practical matter, be achieved on an evolutionary course which starts with acceptance of current patterns and practices and also provides incentives and supports for developments toward the declared goals.

(4) The national economy as a whole should be the underlying source of financing, both for the development of needed resources for the provision of services and for adequate and assured support of continuing functional performances.

(5) To be acceptable as well as viable, the program design should be based on a partnership of

(a) national public financing, "monolithic" as in our national social insurance, and

(b) private provision of the medical care services, "pluralistic" through self-

Issues in Health Services-A Report and Annotated Bibliography 5-8 (National Center for Health Services Research and Development Report, Nov, r970).

${ }^{13}$ Falk, Group Practice Is Pattern of the Future, IoI Mod. Hosp., Sept. I963, at II7; Note, The Role of Prepaid Group Practice in Relieving the Medical Care Crisis, 84 Harv. L. Rev. 887 (I97I). 
elected diversities among providers of services, their location, organization, professional and fiscal operations, and participation in planning and administration.

(6) Continuing financial supports should be assured through

(a) taxes which are earmarked for medical care and which automatically adjust to the state of the national economy,

(b) matching or supporting appropriations from general revenues, made as nearly automatic as possible, and

(c) utilization of the total yield through the mechanism of a permanently appropriated trust fund, avoiding the uncertainties of annual appropriations.

(7) The program's fiscal operations should rest on prospective annual budgets for the support and compensation of those who provide medical care services and goods, in order to rationalize planning and to contain costs within levels determined by national decisions.

(8) To assure the worth of services supported by public funds, the design of the program should provide for standards of quality, and the administration should be required to implement all practical measures for the observance of such standards.

(9) Administration of the program should involve not only the public authority but also representatives of both consumers and providers of services.

(Io) Mandatory provisions should assure public accounting of program operations and performances.

This series of specifications identifies the desirable major criteria by which, I believe, we should measure the promise of a national health insurance proposal and against which we should weigh the relative advantages of one proposal over another. ${ }^{14}$

\section{IV}

\section{Some Current Proposals}

There are already, at this writing, perhaps a score of proposals for national health insurance. They differ in many respects but especially in the manner in which or the extent to which they would deal with the insurance issue and would move to influence the delivery system as well. ${ }^{15}$ Seven, selected across the spectrum, are summarized here to indicate their main specifications-without undertaking to cite many duplicating legislative introductions or many variations in their details.

\footnotetext{
14 This formulation of specifications substantially reflects the results of studies and discussions in a technical subcommittee (of which the present author is chairman) of the Committee for National Health Insurance. These specifications (and many additional related items) served as the framework for the preparation of the Health Security Act, S. 3 and H.R. 22, 92d Cong., Ist Sess. (197I), discussed infra.

${ }^{15}$ Proposals to improve Medicare and Medicaid being considered in the House Committee on Ways and Means and in the Senate Committee on Finance are omitted here because they concern programs for limited sectors of the population, those persons sixty-five and over and those persons who are public assistance recipients or are medically indigent near-poor.
} 


\section{A. "Catastrophic" Illness Expense Plans (Senator Long)}

These are proposals for federal intervention to provide insurance protection against costs which exceed those commonly covered by privately purchased insurance. The bill introduced by Senator Long and other senators is intended to provide a supplement to private (basic) insurance protection for substantially all persons under sixtyfive years of age and a supplement to provisions for public assistance recipients and medically indigent persons under the federal-state programs of Medicaid (title XIX of the Social Security Act). ${ }^{16}$ Under Senator Long's bill, eligibility for benefits would extend to all persons under sixty-five who are fully or currently insured under the national Social Security program and to their spouses and dependent children. Special provisions are also made for extension to federal employees and, through voluntary "buy-in", to employees of state and local governments.

Under the Long bill, the benefit categories (covered and excluded) are the same as for those sixty-five and over under Medicare (title XVIII of the Social Security Act), but without upper limits on hospital days, extended care facility days, or home health visits. It would take over expenses (a) beyond those incurred for sixty days of hospital care per individual in a year, subject to coinsurance of one-fourth of the Medicare daily coinsurance for hospital and one-eighth for extended care services, and $(b)$ after a family has incurred $\$ 2,000$ of expenses in a year for medical and related covered services, subject to copayments of twenty per cent. The administrative mechanisms would be the same as for Medicare, so that this would be federally-provided insurance to pay for privately provided services through insurance carriers acting as agents of the governmental authority.

The first year cost estimate is $\$ 2.5$ billion. The program is to be self-financed by contributions into a separate trust fund, the tax rates for employers and for employees rising (I972-1980) from 0.3 to 0.4 per cent of taxable payrolls up to $\$ 9,000$ per employee, with the same tax rates applicable to self-employed persons.

\section{B. "Medicredit" (Amercian Medical Association)}

A widely advertised proposal for new financial support to enlarge the purchase of private insurance was developed by the AMA.17 It would increase the availability of funds for such purchases on behalf of persons under age sixty-five by having the U.S. Treasury bear the expense, either through the issuance of purchase certificates or through allowance of credits against income tax obligations.

Individuals under sixty-five and having no income tax liability would be eligible to receive a certificate for the full payment of the premiums for a "qualified" health care insurance policy or plan for a twelve-month period. (No amount, limit, or control on premiums is specified in the bill.) Others having some income tax liability may receive either a credit against such liability for premiums incurred,

\footnotetext{
${ }^{10}$ Catastrophic Illness Insurance Act, S. 1376, 92d Cong., Ist Sess. (r97r).

${ }^{17}$ Health Care Insurance Act of 1971, H.R. 4960, 92d Cong., Ist Sess. (197I).
} 
or a certificate for use in payment to a qualified carrier, the tax credit amount ranging from 100 per cent of the allowable premium for those with no income tax liability down to ten per cent for those with liability exceeding $\$ 8 g 0$ in a base year.

A qualifying insurance policy is required to make provisions with respect to institutional, medical, and catastrophic expense coverage without excluding protection against pre-existing conditions; must be noncancellable and renewable; and must provide for payment of usual and customary charges for service. Minimum basic and catastrophic benefits covered and excluded are specified. The basic benefits would be subject to a deductible of $\$ 5^{\circ}$ for each inpatient stay in a hospital or extended care facility, and to twenty per cent coinsurance of up to $\$ 500$ of family expenses in a policy year for emergency or outpatient hospital services and twenty per cent coinsurance of the first $\$ 500$ of family medical expenses in the year. The catastrophic benefits would be amounts in excess of family expenditure amounts graduated according to taxable income (ten per cent of income up to $\$ 4,000$, plus fifteen per cent of $\$ 4,000$ to $\$ 7,000$, plus twenty per cent of the excess over $\$ 7,000)$, less family expenditures to meet deductibles and coinsurance for basic benefits.

The program would be administered by a Health Insurance Advisory Board constituted with the Secretary of HEW as chairman and the Commissioner of Internal Revenue and nine public members, of whom a majority would be practicing physicians, appointed for rotating four-year terms. This board, though identified as "advisory," would prescribe regulations, establish federal standards to be used by state insurance departments when qualifying an insurance company or plan, and would plan and develop programs concerned with quality of care, utilization of financial resources, health manpower, facilities, utilization review, and so forth. The state agencies would qualify the carriers, each being required to participate in an assigned-risk pool and to offer catastrophic coverage along with basic coverage. At the request of a state, DHEW would enter into an agreement under which all who are eligible for benefits under this bill and under Medicaid might subscribe to a qualified policy or plan.

The bill would create a trust fund to receive authorized appropriations from general revenues in an amount equal to the aggregate amount of premiums paid from the fund through the redemption of certificates presented to DHEW. The Internal Revenue Code would be amended to allow premiums paid for a qualified policy or plan as a credit against tax obligation. An employer would be permitted to claim only one-half of his health insurance expenses as a tax deduction unless he has a qualified policy or plan in force for his employees.

A spokesman for the American Medical Association has estimated the first-year cost of the proposed program at $\$ 4.5$ billion from the general revenues of the U.S. Treasury. A preliminary estimate from the Social Security Administration puts the cost at about $\$ 15$ billion a year initially. No estimates are available on addi- 
tional costs to the population or on prospective costs in subsequent years. The bill includes no amounts, limits, or other regulatory controls on insurance premiums and no provision to fund the federal costs of the program.

\section{C. "Healthcare" (Health Insurance Association of America)}

A much more comprehensive program which relies heavily on private insurance was developed for an association of insurance companies and was introduced in the House by Representative Burleson and others and in the Senate by Senator McIntyre and others. ${ }^{18}$

The basic insurance proposal, applicable to substantially all residents (except those sixty-five and over eligible for benefits under Medicare), provides financial incentives for individuals, and for employers on behalf of their employees, to purchase an "approved" insurance policy with the premiums open to sharing (at a rate not specified) between employer and employee. The incentive is a full offset against otherwise taxable income for premiums paid for approved policies, as against onehalf offset for other insurance purchases and with a ceiling of $\$ 150$ for individuals. A corresponding system would be established, through election by the states, of qualified state health care plans for public assistance recipients under federally aided programs, for the poor and near poor (defined by income ceilings) and for "uninsurables." The poor are to pay no premiums; the others would pay premiums graduated against income. There would be ceilings on premiums to be paid by the state (with federal sharing) to the private insurance carriers.

An approved insurance policy must provide at least stated minimum benefits with prescribed copayments and with maxima on the deductibles. The prescribed benefits are to become available by specified dates, phased in three categories over a period of six years unless deferred by the President. Benefit payments would be controlled by reference to approved institutional or reasonable practitioner charges. Insured persons are to have the option of electing to be served through approved health maintenance organizations (HMOs). The federal government would provide seventy to ninety per cent of the cost of benefits under an approved state plan for the needy and others, and the states would provide non-federal shares. Federal grants under titles V and XIX of the Social Security Act would require that a state have such a plan after July I, I973.

Systems improvements, to augment resources for medical care, are proposed through a series of broad provisions: support loans and scholarship grants for students training in the health professions, project support grants to educational institutions, and special grants for training and support of personnel for areas of critical health manpower need; fiscal supports (grants, loan guarantees, and loans), through the states, for construction, modernization and initial operation of health care centers; establishment of a Council of Health Policy Advisers and a requirement

\footnotetext{
${ }^{18}$ National Health Care Act of I97I, S. I490 and H.R. 4349, 92d Cong., Ist Sess. (I97I).
} 
that the President shall make a comprehensive annual Health Report to the Congress; and strengthened supports for comprehensive health planning in the Public Health Service and in the states.

Thus, the Healthcare bill leans primarily on the private insurance industry, but with subsidies from governmental funds and authority, and with encouragement to government for health program planning and resource development. It leaves Medicare intact, and would provide for absorption of federally aided maternal and child health services and of Medicaid into insurance pools to the extent that benefits under those federal-state programs would be provided under the private insurance policies.

No cost estimates for either governmental or private expenditures under this proposal are available at this time.

\section{D. "Ameriplan" (American Hospital Association)}

A committee of the AHA has submitted the outlines of a new nationwide system for both the delivery and the financing of medical care. ${ }^{19}$ Since the specifications are available only in broad and general terms, and have not yet been formulated as a legislative proposal, the plan can be viewed only in its outlines.

Ameriplan intends to make provision with respect to all needed personal health services for everybody. The potential benefits are presented in four separate categories: $(a)$ health maintenance, $(b)$ "standard benefits" (with various possible limits and copayments), (c) catastrophic illness benefits (with various possible limits and prior expenditure corridors), and $(d)$ supplemental benefits (variable according to need, ability to pay, and purchase). Eligible persons are also in four categories: (i) the poor (not defined), (ii) the near-poor (not defined), (iii) the aged, and (iv) all other persons. Financing would depend on funds from three sources: (i) federal general revenues, (ii) social security payroll taxes, and (iii) private resources of individuals or employers. Payments, whether derived from one source or a combination of sources, would be adapted to the category of benefits for each category of eligibles.

These combinations are summarized in Table I. Persons who register with a "health care corporation" (HCC) and purchase or are provided the "standard benefits" would become eligible for the health maintenance and catastrophic illness benefits financed by the compulsory social security payroll taxes, whether or not they also purchased supplementary benefit coverage privately. The aged would continue to be served through Medicare, wholly financed by payroll taxes, and privately purchased supplemental coverage. The poor would have all their benefits financed by the federal government and the near-poor by combinations from all sources.

\footnotetext{
10 american Hospital Association Special Committee on the Provision of Health Services, Ameriplan-A Proposal for the Delivery and Financing of Health Services in the United States (r970).
} 
TABLE I

Sources of Funding for Benefit Categories Under AHA's "Ameriplan"

\begin{tabular}{lcccc}
\hline & \multicolumn{4}{c}{ Source of financing for the } \\
Benefits & Poor Near-poor Aged Others \\
\hline Key & $\left\{\begin{array}{l}\text { G: Federal general revenues } \\
\text { S: Social security payroll taxes } \\
\text { P: Private funds }\end{array}\right.$ \\
Health maintenance* & G & G + S & S & S \\
"Standard benefits" $\dagger$ & G & G + P & S & P \\
Catastrophic illness* & G & G + S & S & S \\
Supplemental coveragest & G & P & P & P \\
\hline
\end{tabular}

-Uniform "packages" of benefits.

+ Variable as to scope of benefits.

Source: Adapted from "Ameriplan," 6 Perspective 3 (Conn. Blue Cross, I97I).

The service delivery system is focused on geographically identified HCCs. These are to be developed primarily by providers of care under state auspices and could take many forms for the organization and delivery of services. They would be required to be in accordance with federal law and regulations as to scope of benefits, standards for personnel, institutions, quality of services, and so forth. They would be designed to serve, say, 60,000-600,000 persons each, and each would be required to provide its enrollees-through its locally owned or organized resourceswith health maintenance, primary, specialty, restorative, and health-related custodial care; to encourage enrollments and participation of all community physicians and institutions; to be responsible for professional review, quality maintenance, training of health manpower; and so on. The HCC would be compensated for health maintenance services on a capitation basis and for other services at prospectively determined rates, each category of rates to be approved by a state agency. Within an HCC, providers would elect the method of their compensation.

Ameriplan is intended to function under national legislation which would create a National Health Commission; enact taxes on employed and self-employed persons (but apparently not on employers) ${ }^{20}$ authorize appropriations from general revenues for support grants and loans to aid in the formation and initial operation of HCCs and for payment of services to the poor and near-poor. Each of the fifty states would then enact legislation for the organization of state and regional health commissions and the formation and approval of HCCs. The AHA report provides no estimates of expected costs. ${ }^{21}$

\footnotetext{
20 This may have been an oversight or an unintended result of loose draftsmanship.

${ }^{21}$ It is reported that the AHA's Ameriplan is being formulated as a bill for legislative consideration. A bill introduced by Senator Pell bears some similarities to some major parts of Ameriplan. Senator Pell's bill, Minimum Health Benefits and Health Services Distribution and Education Act of 197I, S. 703, 92d Cong., Ist Sess. (1971), also proposes provision of health service benefits through geographically organized community health and education corporations.
} 
One can commend the objectives of the proposal, but evaluation has to take account of the fractionization of services into several "packages," the marginal problems in defining eligibles and in their changing status, the financing from and through multiple sources, the reliance on federal legislation and annual appropriations and on legislation and implementation in the fifty states, and the continued dependence on variable private purchase of benefits.

\section{E. Expanded and Improved Medicare (Senator Javits)}

Senator Javits of New York has submitted two bills which propose, first, improvements in the Medicare for persons sixty-five and over and, second, the extension of Medicare into a program of national health insurance and systems improvement for all persons not already otherwise eligible for the benefits of the existing program. ${ }^{22}$

The proposed improvements of Medicare take the form of combining parts $\mathrm{A}$ (hospital) and B (medical), including widow, widower, and disabled beneficiaries among the covered eligibles under the Social Security and Railroad Retirement acts, eliminating the premiums currently being charged for part B (part A is a Social Security paid-up insurance). These changes would be effective July I, r972.

The health benefits of Medicare would then be extended to the general public through a new title (XX), which would absorb title XVIII (effective July $x, 1974$ ) and add new benefits: certain prescription (maintenance) medicines, with $\$$ I copayment per prescription (effective July I, I974); annual physical examinations, with copayment up to $\$ 75$; and dental services for children under eight years of age (effective July I, I975). The benefits would be made available (presumably) through contracts with insurance carriers or through agreements with comprehensive health service systems; and may also be provided through employer plans with benefits superior to those required as a minimum.

Administration would in general follow the current pattern in Medicare. Special provisions are made, however, for new studies of drug utilization; for agreements with any state for administration of the program; for requirement that each participating agency, organization, or insurance carrier shall use its best effort in contributing to the improvement of the program; and for new studies on effective methods of compensation for health services, with authority for the Secretary (with the approval of the President) to develop overriding amendments in the statutory provisions after specified consultations. The program is, by declaration, intended to make extensive use of the private insurance industry. In the event it is not prepared to cooperate, the bill provides for organization of federally chartered national health insurance corporations and their utilization by the Secretary as agents in administration.

The expanded national health insurance would be fianced by a combination of (a) social security taxes on wages, payrolls, and self-employment income (up

${ }^{22}$ National Health Insurance and Health Services Improvement Act of $x 97 x$, S. 836, 92d Cong., Ist Sess. (1971); Local Comprehensive Health Services Systems Act of 1971, S. 837, 92d Cong., rst Sess. (197I). 
to $\$ 15,000$ per person), the rates moving up from 0.7 per cent on each in 1972 to 3.3 per cent in 1976 and thereafter, and (b) appropriations to a trust fund from federal general revenues equal to fifty per cent of the fund's income from the earmarked taxes (one-third of the total).

Systems improvements would rest principally upon encouraging the development of local comprehensive health service plans to function as prepayment plans, whether through group practice or not. To this end the Secretary is authorized to enter into agreements with various kinds of approved organizations (comprehensive group-practice health service systems, insurance carriers offering equivalent contracts, or employer-employee plans with superior benefits and exemption from payroll taxes) for the provision and availability of the prescribed benefits (and also of additional services) to identified population groups on a cost-reimbursement or capitation payment basis. To stimulate the development of organized systems, appropriations are authorized for grants and loans to help pay the costs of planning, initial deficit operations, modernization, and construction or rehabilitation of needed facilities (especially for ambulatory services and especially for needed developments in urban or rural poverty areas).

No formal cost estimates are available for the program proposed by these bills.

\section{F. The Nixon Administration Program}

The program advocated by the Administration ("a new National Health Strategy") ${ }^{23}$ includes three major elements, among others: an insurance program for employed persons and low-income families; ${ }^{24}$ systems improvement especially through the development of "health maintenance organizations" (HMOs); and supports for meeting health manpower needs generally and for better organization of health services delivery. ${ }^{25}$

The basic insurance proposal would require all private employers to provide, for all their employees having susbtantial employment, a basic coverage which meets at least the minimum standards prescribed (without affecting existing health insurance provisions through an employer until expiration of an underlying contract). This coverage would be furnished at the expense of the employers and employees. In addition, low-income families which have children and which are not covered by the basic plan would be covered by a separate Family Health Insurance Program (FHIP), made compulsory through premium withholdings for those aided under the proposed Family Assistance Plan (FAP) or whose state supplementary supports equal or exceed the insurance premium amount, with a sliding-scale sharing of costs by them from their family income and by the federal government from general revenues.

\footnotetext{
${ }^{23}$ Message from the Prestdent, supta note 8.

${ }^{34}$ National Health Insurance Partnership Act of r97r, S. r623, 92d Cong., Ist Sess. (I97I).

${ }^{25}$ Health Maintenance Organization Assistance Act of I971, S. I182, 92d Cong., Ist Sess. (197r); Health Manpower Assistance Act of I97r, S. II83, 92d Cong., Ist Sess. (197I).
} 
The basic plan benefits ${ }^{26}$ must extend at least to a specified spectrum of services (inpatient hospital services, physician attendance in and out of hospital, maternity and well-baby care, laboratory and X-ray services, without arbitrary limits up to a maximum of $\$ 50,000$ of costs per person; but the requirements do not extend to other professional attendance, psychiatric care, dental care, or medicines and appliances). The availability of benefits would be subject to various deductibles and coinsurance payments (for example, the first two days of hospital room charges, $\$ 100$ of expenditures per person up to three in a family for other services provided, and twenty-five per cent of all covered charges incurred), but all further cost participation would be waived after total expenditures of $\$ 5,000$ for covered services in a calendar year. Services for conditions (except pregnancy) pre-existing when insurance coverage begins for an individual would not be covered for the first six months.

For low-income families, the benefits under FHIP would be limited to thirty days of inpatient hospital or other institutional care, emergency services and physician's visits, laboratory services, maternity care, and family planning services. The premiums would be graduated (from none for the poorest up to $\$ 100$ a year for those in the highest of five classes specified by family size) as would also the deductibles and copayments. The Secretary would be authorized to implement this plan through contracts with public or private agencies or through insurance carriers.

Under both the basic plan and FHIP, covered persons are to have the option of enrolling for their benefits (services) in a HMO which meets the prescribed standards (if there is one in the community).

Payments to providers would follow the patterns in Medicare (that is, "reasonable charges" to physicians and "reasonable costs" to hospitals), with global payments to HMOs. A participating hospital would be required to have a utilization review plan, and payments under the program would require observance of the provisions of Professional Standards Review Organizations (PSRO) as proposed for Medicare and Medicaid.

Insurance carriers which provide basic plan insurance to employers would be required to participate in insurance pools that would be available to self-employed persons, to small employers (having less than roo employees), and to others not covered by basic or FHIP insurance coverage. Employers would be free to opt out of the system by undertaking self-insurance. Medicaid would be restricted to the needy aged, blind, and disabled and could, at a state's option, extend to medically needy persons in these categories.

The required basic insurance would be financed by the employers and their employees, with the latter to pay not more than thirty-five per cent in the first two and a half years and twenty-five per cent thereafter. ${ }^{27}$ The federal share of the compulsory

\footnotetext{
${ }^{20}$ The plan was said by its congressional sponsors to have been patterned after the low-option, government-wide indemnity benefit plan under the Federal Employees Health Benefits Act. II7 Cono.

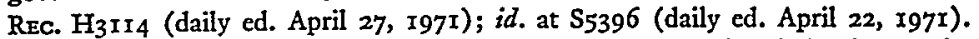

${ }^{27}$ The administration's basic bill was to have been introduced simultaneously in the House of Repre-
} 
FHIP costs would be met from federal general revenues, but there is no provision for appropriations in the bill. The principal sponsor in the House (Rep. Byrnes) has said that, when first effective, the cost of the basic plan for a married employee is estimated at about $\$ 390$ per year, with the employer paying about $\$ 250^{28}$ The Senate sponsor of the bill recorded an estimate that the FHIP would cost approximately $\$ 1.2$ billion in additional federal funds in its first year if all eligible families participate. $^{29}$

For systems improvement with respect to health manpower resources, the program includes (in S. II83)-along with general supports for professional and technical education and training-various special provisions pertinent to the insurance and delivery program: special project grants for the training of medical students and others to use the team approach for delivery of services; grants and contracts with schools of medicine to assist in developing and operating HMOs; and authorization to reduce loan obligations of students engaged in primary care in medically underserved areas.

For systems improvement specifically with respect to delivery of care, the program emphasizes the encouragements to develop, expand, and utilize HMOs, particularly in medically underserved areas, through grants for planning, loans or loan guarantees for facilities construction, and initial operating supports (for up to three years) for those HMOs which would function in or expand into medically underserved areas. Requirements for approval as an HMO, whether group practice or not, are substantially the same in S. I623 and S. II82, and extend to scope of services, payment to the group on an aggregate sum or capitation basis, meeting standards for promptness and quality of services, provision of an open enrollment period, and so forth. State laws or regulations inconsistent with contracted obligations of an HMO bearing on efficient and economical provision of services would be inapplicable (by specification in S. 1623). The amounts of money to be available for these developmental purposes are not specified (in S. II82).

The initial effective date for all provisions of the Administration's program would be July I, $1973^{30}$

sentatives and the Senate, but it was delayed in the former by objections to the proposed employer financing requirement with respect to "small" employers, lest the new or increased cost for such employers should prove to be excessive or burdensome or would adversely affect employment of low skill workers. When introduced, the House version differed from S. I623, supra note 24 , by providing that if the cost to any employer would exceed $4 \%$ of average wages, DHEW would pay the excess with respect to up to ten employees. H.R. 774I, 92d Cong., Ist Sess. $\$ 602$ (d) (I97I).

${ }^{38}$ ri7 Cong. Rec. H3rit (daily ed. April 27, I97x).

${ }^{20}$ Id. at $\mathrm{S}_{5393}$ (daily ed. April 22, I97I).

${ }^{30} \mathrm{~A}$ variant of the Administration's program was proposed by Senators Scott and Percy. This bill proposes federal catastrophic illness expense coverage with respect to inpatient and home health services for all residents and for nonresident citizens, to be financed from Social Security payroll and selfemployment taxes and from general federal revenues; a voluntary outpatient health maintenance insurance plan through private insurers, with graduated federal support for low-income families; grants and loans for planning and development of HMOs; and support to increase health manpower resources through student loans and capitation grants to existing and new medical schools. Health Rights Act of r97r, S. 1598, 92d Cong., rst Sess. (1971). 


\section{G. The Health Security Act (Committee for National Health Insurance; AFL-CIO; Senators Kennedy et al. and Representatives Griffiths, Corman et al.) $)^{31}$}

The proposed act presents the program developed by the Committee for National Health Insurance ("The Committee of 100") and by the AFL-CIO with the declared objective of making personal health services of good quality available to the entire population of the United States. It therefore embraces a system of national health insurance and simultaneous provisions for the improvement and development of resources for medical care.

The population coverage of the proposal extends to substantially all persons resident in the United States, and all would be eligible for benefits without either contribution histories or means tests. The benefits to be available include all needed personal health services from all available qualified providers, including services for prevention and early detection of disease, diagnostic and treatment care, and rehabilitation services, from physicians and other qualified individual providers, and from hospitals and other institutions, inpatient and ambulatory. With a few exceptions, there would be no arbitrary cutoff dates for services, and there would be no deductibles and no copayments required from persons served. Four exceptions to unlimited care according to need are with respect to: dental care (surrounded initially by age limitations, the benefits are to be broadened as rapidly as feasible); skilled nursing home care (limited as to duration); psychiatric consultations (limited to twenty consultations in a benefit period if not an element of organized comprehensive care or provided by a participating institution) and psychiatric hospitalization (limited to active treatment up to forty-five inpatient days in a general or psychiatric hospital); and prescribed medicines, which are not covered unless provided through a hospital or organized care program or required for treatment of chronic disease or conditions for which drug therapy is costly.

Specifications for qualifying providers, individual and institutional, are patterned after those developed under Medicare but go further in providing for requirements as to continuing education and in permitting interstate personnel mobility for the federal program despite state requirements of licensure. Payments to individual providers may be made through alternative methods (fee-for-service, capitation, stipends, and so forth); to hospitals and institutional providers on the basis of negotiated prospective budgets; to comprehensive health service organizations and to professional foundations (which meet prescribed qualifications) on the basis of capitation amounts (or through alternative negotiated methods); and to other providers (for services, medicines, or appliances) on adaptive bases.

Financing of the costs is proposed through taxes earmarked for a trust fund: on earned and unearned income up to (initially) $\$ 15,000$ a year, one per cent for employed persons and 2.5 per cent for self-employed and nonemployed persons; 3.5

\footnotetext{
${ }^{31}$ Health Security Act, S. 3 and H.R. 22, 92d Cong., Ist Sess. (197I).
} 
per cent on employers' payrolls; and an amount from general federal revenues which matches income from these taxes. A portion of the amount available in the trust fund for obligation during a year is to be segregated in a health resources development account-two per cent for the first two years, increasing so as to reach five per cent in the seventh year. The amount available to pay for benefits each year, mainly determined by the income from taxes and matching amounts, is to be allotted among regions. Initially, the allotments are to be in relation to current levels of expenditures for medical care services, with subsequent modification according to regional needs so as to work toward regional equalizations. Within each region, the allotment is to be subdivided for categories of services so as to provide the global amounts available for payments to providers; and the categorical suballotments are then to be allotted to subregional health service areas.

Broad policies and diverse specific guidelines are laid down for the planning and implementation of resources development-to improve the supply and distribution of health service personnel and the location of facilities and for the organization and delivery of health services, with participation by health planning agencies in the states. The guidelines extend to fiscal and technical supports for education and training of needed personnel, with special supports for members of minority groups; incentives for the development of comprehensive health service organizations; provisions for coordination and linkages among institutional providers; and supports for services needed in underserved urban and rural areas. Appropriations to the health resources development account from general revenues ( $\$ 200$ million the first year and $\$ 400$ million the second) are authorized to initiate these activities between enactment of the benefit program and the effective date for availability of benefits.

Restrictive state laws that would obstruct program developments are declared inoperative in relation to provision of benefits under this program. This applies to licensure, the functions permitted to various categories of practitioners (if they meet national standards), and to corporate practice of medicine in hospitals and comprehensive health service organizations. If a comprehensive organization cannot be incorporated in a state for various stated reasons, it may be given national incorporation and authorization to function under the proposed program.

The guidelines for resources development specify that the undertakings under this program shall supplement and not absorb or supersede existing programs in this field. The Secretary is directed and authorized to coordinate established programs with the new programs to be developed under this bill.

Administration is assigned to public authorities: a full-time national Board (under the Secretary of HEW), which is to function with a statutory national Advisory Council and with professional and technical advisory committees and to operate through regional and local offices, assisted by advisory councils with consumer and professional representatives. Provisions are made for hearings and judicial review; for a comprehensive series of prospective studies; and for special 
studies with respect to such matters as benefit provisions for American citizens when abroad, needs for long-term care, coordination with other federal health benefit programs, and malpractice liabilities.

The Medicare and federal employee health benefit programs would be absorbed into the Health Security program and would be repealed. Federal aid for Medicaid, vocational rehabilitation, and maternal and child health services would be phased out except as the proposed Health Security program does not take over their service provisions.

The sponsors of the Health Security program estimate that if the program had been in operation in a recent year it would have extended to personal health services which account for approximately seventy per cent of current expenditures, and that this percentage would be applicable to the early years of program operations-with the percentage rising later on. Assuming somewhat more moderate cost escalations for the years ahead than we have recently experienced, they estimate that the program would involve about $\$ 58$ billion in fiscal year 1973-74. In subsequent years, the dollar figures would be higher because of expansion of benefits and growth of population, and they would be higher or lower depending on whether the national price indexes move upward or downward; but since the bases for earmarked taxes are expected to move correspondingly, the tax rates should be substantially stable and the fiscal resources in balance with the fiscal obligations of the program. DHEW, assuming a higher rate of cost escalation if there is no new program intervention, estimated that current total expenditures are expected to reach approximately $\$ 95$ billion for personal health services in that fiscal year, so that on this basis the Health Security program (extending to seventy per cent of the total) would involve about $\$ 67$ billion in its first full year of operation. The sponsors expect the Health Security program to moderate future escalation so that the program expenditures will involve not new or additional amounts but only a controlled rechanneling of funds (mainly through public flows) that would otherwise be spent for the services (mainly privately and uncontrolled).

The effective date for the Health Security benefits would be July $x$ of the second calendar year after the year in which enacted. However, in the two years prior thereto, resources development and improvments are to be initiated through the funds authorized to be appropriated therefor. The taxes enacted to finance the program would become effective January $\mathrm{I}$ of the second year after enactment.

\section{Evaluation and AdVOCACY}

Each national health insurance proposal has limitations because, if for no other reason, it is only part of a comprehensive national health program. Whether focused on insurance or on both fiscal solutions and systems improvement, it is primarily concerned with personal health services and does not deal comprehensively, if at all, 
with such related aspects as basic health manpower and facilities needs or with the community-wide and environmental services. While recognizing such limitations, we are nevertheless justified in evaluating each proposal against the guidelines suggested earlier. We have a right to ask of each proposal what it would do for the long-run, and not merely for the short-run, toward dealing with the current crisis in medical care and toward resolving the underlying causes of crisis. We can accept a program with limited objectives for what it is, but we should not be misled by rhetoric or need for political compromises that a limited program is a substitute for an adequate program.

By these benchmarks we have only a limited quarrel with proposals like Senator Long's for national provision of "catastrophic" insurance. It does not profess or pretend to deal with the major or underlying causes of crisis; it only attempts to deal with a need that obtains because of inadequacies in the current insurance provisions for those below the statutory age of eligibility for Medicare. Though probably at the price of contributing to further escalation of costs, it would provide limited, and presumably temporary, fiscal supports and relief for a system which needs more extensive overhauling.

The AMA's "Medicredit" invites a different kind of commentary. Obviously, it meets nearly none of the criteria submitted for evaluation. Fundamentally, it merely proposes to draw money from (or to withhold payments to) the federal treasury in order to support the private purchase of more private insurance. I do not believe we can accept any plan to use the national fiscal resources merely or mainly to pour more money into the fiscal channels of the medical care system, even if the undertaking is weighted in favor of the lower rungs of the taxable income ladder. Such a design would do little or nothing more than provide more payments for services from the already strained or overburdened resources for medical care. The proposal must be expected to support increased demands on these resources or else it has no meaningful point, but without increased controls over the system and its utilization much of the increased demand would be of the wrong kinds. The plan would surely invite further and steeper escalation of prices, charges, and costs, pointing to a larger imbalance in services and possibly to fiscal disaster. There can be little consolation in calling the program "voluntary" despite the compulsory method for obtaining the needed funds from the national treasury.

The proposal from the health insurance companies incorporates various desirable provisions. Nevertheless, it should be rejected because it would, in the main, use public funds as incentives and subsidies for private insurance plans that may be only a little better than those that have already failed us. We should not use the authority and resources of government to encourage continued open-end public payments for services which are inadequately guided or controlled. We should not follow inadequate policies in order to preserve and protect the vested interests of fiscal institutions in the marketplace. Medicare, regarded as a national health in- 
surance for the aged, should have taught us two lessons. First, it would be disastrous to build into a broader national health insurance continuing unlimited distribution of signed blank checks on federal funds in order to pay institutional providers whatever costs they incur or to pay personal providers not the fees in negotiated fee schedules but whatever charges they establish as their usual and customary fees. And, second, it would be a grievous mistake to incorporate in any new scheme all the complexities which have made various private insurance patterns and Medicare almost incapable of public understanding, cumbersome and expensive in administration, and incapable of supporting-or indeed capable of delaying-needed improvements in the organization and delivery of good medical care. We have ample knowledge and experience on which to base the design of a system of service benefits as against indemnity reimbursements, with adequate payments to both the personal and institutional providers of health care, and without the gimmicks of fractionated services, deductibles, coinsurance, and other barrier payments that operate largely to frustrate the primary purposes of the program. Many operating service plans attest to this.

Inspection of the American Hospital Association's “Ameriplan" proposal convinces me that we cannot afford to rely on a program which promises more-not less-complexity resulting from pluralism in financing multiplied by pluralism in the provision of care or on state-by-state action. That much pluralism, coupled with dependence on the states to carry out a national plan, is an invitation to uneven action at the best and to inaction at the worst. Surely, there are virtues in pluralism and in gradualism, and there are advantages from adaptation to local scenes. But these also become invitations to both warranted and unwarranted compromises with vested interests and the status quo. This is now well documented by experiences with federal-state programs of medical care. Perhaps when it is being spelled out in precise legislative form, "Ameriplan" will be simplified and will include more promising leverages for systems improvement and cost containments so that it will seem more deserving than it does now.

Senator Javits' proposals (S. 836 and S. 837) are obviously compromises between Medicare-from which he would move in stages toward increasing the adequacy of benefits-and the administration and Kennedy proposals, of which he is also a sponsor. The strengths of the national approach are, however, offset by the continuing reliance on the private insurance carriers and their patterns to implement the prospective program; and this could be regarded as a fatal weakness in a plan which does not incorporate budgetary restraints or adequate alternative controls. The proposal has the virtue of providing for various expansions of resources and improvements in the delivery system along with assured governmental fiscal supports, though these are developed better and more fully in the Kennedy bill.

In view of the urgency of the national need, it is gratfying that the national Administration has made commitments to "building a national health strategy," 
especially because the program which has been outlined by President Nixon and HEW Secretary Richardson has some elements of comprehensiveness and immediacy. Also, it proposes some supports for needed health manpower and facilities, and some incentives for improved availability of care in underserved areas. By encouraging the development of group practice and solo practice within the framework of Health Maintenance Organizations (HMOs), it would invite system improvements for the availability and delivery of care.

Major implementation and financing are being proposed, however, through reliance mainly on the private purchase of private insurance, required of employers, but with no discernible restraints or protections against the wastes, inefficiencies, and extravagances inherent in such a pattern. This major aspect of the Administration's "National Health Strategy" is surprising, since so much of program performance would then be entrusted to the insurance carriers whose patterns of program design and operation have been providing the pattern of service fractionations and the substantial invitations to regrettable cost escalations and fiscal resistances to system improvements. "Cost consciousness" was given prominent mention in the President's Message to Congress and in the Secretary's Congressional testimony, but within their bills it is plain that the fiscal soundness and viability of their proposals are being left to the play of forces in the marketplace and to the "cost-consciousness" of those would pay the costs. This is suprising and disappointing, since the marketplace and the payment pattern have already dem onstrated on massive and all but disastrous scales their inability to stay the inflation of prices and costs or to support needed improvements in the system.

Further, the Administration's program would seem to be little more than aggregation of loosely related parts: the required employer-purchased private insurance for employees and dependents, with employer and employee sharing the premiums; a payroll-tax-supported national Medicare for the aged; a federally subsidized Family Health Insurance Plan (FHIP) for low-income families with children; a continuing federal-state Medicaid program for the aged, blind, and disabled; and additional insurance "pools" for small employers, for the self-employed, for those outside the labor force, and others. Such an aggregation of substantially separate and independent parts would inevitably result in almost endless marginal problems of jurisdictions, interchanges of people between segments of the program, and unmanageable confusions from diversities in the financing patterns. Such an aggregation of parts, with their different eligibilities, inclusions and exclusions, and such pluralism in financing, cannot fail to compound further the intricacies, the confusions, and the inadequacies with which the medical care scene is already more than sufficiently plagued. The Administration's program, if enacted, would compound its inadequacies by its mystifications for the population that would have to live with it.

The adequate and desirable program, I believe, is clearly contained in the 
"Health Security" program designed by the Committee for National Health Insurance (CNHI) and the AFL-CIO and contained in the Kennedy-Griffiths-Corman bills, which have bipartisan sponsorship. This proposal has the dual objective of a system of national health insurance interlocked with a simultaneous system of resource improvement and development, and is in substantially strict accord with the guidelines for evaluation set forth earlier in this paper.

Admittedly, in such a program which starts from where we are, the needed services cannot be wholly comprehensive and adequate initially, and several benefit limitations are accepted; but provisions are made for their elimination as rapidly as possible. Otherwise, the program is without deductibles, coinsurance or other direct payments by patients for services, or arbitrary limitations on needed care. Control or rationing of services would rest on professional decisions according to the patient's needs, not on his ability to pay. Extensive special provisions are included to support the development of nonfractionated and comprehensive care, especially through comprehensive group practice, and to encourage other broad and diverse improvements in the personal and institutional resources for delivery of good care. This is of the essence; without such support and encouragement no proposal can meet the national needs. Further, enactment of the Health Security program would mean elimination of various special systems, such as Medicare, and the phasing out of Medicaid. It would therefore be moving toward simplicity and understandability-as well as toward adequacy-in the delivery of medical care for the population.

This has been used as the basis for a criticism that the program would be "monolithic" and therefore rigid and ill-adapted to desirable flexibility and diversity. This criticism rests on misunderstanding. The financing would be national and "monolithic," as in our efficient and stable national system of social insurance, and as it has to be if it is to exert the needed leverage for system guidance, reform, and improvement. But the services would be available from and would be provided by a "pluralistic" system of resources for medical care-all the possible and diverse providers, as they are and as they would become in the course of time without arbitrary or dictated patterns of organization or practice. I would emphasize this basic partnership in the Health Security program: systematic and secure national funding by the federal government and multiform delivery of medical care by private providers. Indeed, there is more promise of flexibility in the provision of services and in the delivery of care in the Health Security proposal than in any of the others before Congress, because this proposal would unshackle the nation from the current system with its traditional rigidities and its long-standing obstructions against change.

Little emphasis has been given here to the cost figures which are identified with one proposal or another because most such figures lead to misunderstandings for the national scene. It is not enough to know that a partial or limited system, or one of its parts, is expected to cost so much, whether financed through particular taxes, or from general federal revenues, or by imposts on employers as private in- 
surance premiums. The fiscal aspects of each program have to be viewed not only for their impacts on a particular source of funding but also for their place in the total national costs. A limited program may itself involve small costs, but if it has only limited outreach, or none at all, it leaves the nation with a frightening outlook for national expenditures for medical care. On the contrary, if a comprehensive program would involve a governmental outlay as large as the current total of such expenditures, it may still mean only a transfer of expenditures from one set of flows to another. If the comprehensive program uses the leverage of its expenditures to dampen the prospective escalation of national expenditures, its larger number of billions is a more conservative estimate for the national economy than the smaller number of the limited program.

The point may be illustrated by a comparison. On the one hand, the basic insurance plan of the Administration's proposal may be costless to the federal government, except for the cost of administration; but the plan's cost to employers and employees may be expected to be $\$ 255^{\circ}$ billion a year initially, continuing to escalate at ten to fifteen per cent a year, and be moving upwards to staggering levels; and the costs for the Family Health Insurance Plan (FHIP) may have a corresponding outlook, but in this case including a direct parallel impact on federal funds. And this is presented as a relatively conservative proposall The costs of the Health Security program, on the other hand, would seem at first blush to be large-as for any program that undertakes to finance personal health services for the whole population. Its expenditures, however, would be what we as a nation are already spending and would be not new costs but a rechanneling-at a probably much lesser level-of expenditures we will otherwise be making. The built-in provisions for cost containment through budgeting and other controls give promise for future levels of costs which the nation can afford. In short, in evaluating national proposals the proper focus should be on national and not on fractional costs.

The precise allocation of costs among alternative sources of funds is a separable problem; and it is endlessly arguable. I offer no brief here for a particular formula. What matters most is that the pattern for financing and the allocation among sources shall assure the resources needed to meet the requirements of the prospective program. All else involves balance of equity among sources and feasibility in the political arena.

The signs indicate that the nation has become impatient with drifting and with temporary emergency measures, and is seeking a durable resolution of medical care needs. We therefore have a right and, indeed, an obligation to weigh every proposal for national action by exacting criteria: What would it do toward relieving critical shortages in health manpower and facilities? What would it do toward containing costs and their prospective escalations? What would it do toward improving the system for delivery of medical care and its availability for everyone? What would it do toward encouraging new assurances of good quality in medical care? What 
would it do toward providing assured financial support of services for the whole population?

If we ask these questions of each of the proposals on the current scene, it must be evident that the Health Security proposal offers the most promising program. It does not give wholly satisfying answers to all five questions, but it gives more satisfying answers on each of the five than any of the alternative proposals. Like the others, it suffers from its compromises, principally from the explicit undertaking to proceed on an evolutionary course-starting from where we are with respect to medical care, with what resources we have and how we presently use them, and providing supports and incentives for developments that would take us as rapidly as is practical toward the declared goals.

The Health Security program is not merely a physicians' program, nor a hospitals' program, nor a consumers' program. It is a proposed implementation of a national policy, and of a national commitment of national resources, for the availability of good medical care for the whole population. It does not offer a panacea. Instead, it proposes directed evolution which can begin to achieve some consequential improvements at once and can bring us in a brief span of years within reach if not within grasp of our goals for personal health services. It offers the program of choice for national health insurance and systems improvement for medical care. 